\title{
Overexpression of Collagen Triple Helix Repeat Containing 1 (CTHRC1) is associated with tumour aggressiveness and poor prognosis in human non-small cell lung cancer
}

\author{
Zunfu Ke ${ }^{1, *}$, Weiling $\mathrm{He}^{2, *}$, Yuanhui Laii, ${ }^{3, *}$, Xuefeng Guo ${ }^{4}$, Sharon Chen ${ }^{5}$, Shuhua $\mathrm{Li}^{1}$, \\ Yuefeng Wang ${ }^{1}$, Liantang Wang ${ }^{1}$ \\ ${ }^{1}$ Department of Pathology, the First Affiliated Hospital of Sun Yat-sen University, Guangzhou, Province Guangdong, P.R. China \\ ${ }^{2}$ Gastrointestinal Surgery, the First Affiliated Hospital of Sun Yat-sen University, Guangzhou, Province Guangdong, P.R. China \\ ${ }^{3}$ Vascular and Thyroid Surgery, the First Affiliated Hospital of Sun Yat-sen University, Guangzhou, Province Guangdong, P.R. \\ China \\ ${ }^{4}$ Department of Gastrointestinal Surgery, the Sixth Affliated Hospital of Sun Yat-Sen University, Guangzhou, Guangdong \\ ${ }^{5}$ Department of Molecular and Medical Pharmacology, University of California, Los Angeles, 570 Westwood Plaza, Los Angeles, \\ CA USA \\ * These authors contributed equally to this work \\ Correspondence to: \\ Dr. Zunfu ke, e-mail: kezunfu@mail.sysu.edu.cn \\ Dr. Liantang Wang, e-mail: wanglt@mail.sysu.edu.cn \\ Keywords: CTHRC1 non-small cell lung cancer $\beta$-catenin metastasis prognosis \\ Received: August 04, $2014 \quad$ Accepted: August 28, $2014 \quad$ Published: September 29, 2014
}

\section{ABSTRACT}

Collagen triple helix repeat-containing 1 (CTHRC1), a novel oncogene, was identified to be aberrantly overexpressed in several malignant tumors. However, the expression profile of CTHRC1 and its clinical significance in non-small cell lung cancer (NSCLC) remain unknown. In this study, we showed that CTHRC1 was evidently overexpressed in human NSCLC tissues and NSCLC cell lines at the protein and mRNA level. Ectopic up-regulation of CTHRC1 in cancer cells resulted in elevated invasive and proliferative abilities, which were attenuated by the specific CTHRC1 siRNA. The biological effect of CTHRC1 on metastasis and proliferation was mediated by the activation of the Wnt/ $\beta$-catenin pathway. Furthermore, CTHRC1 immunoreactivity was evidently overexpressed in paraffin-embedded NSCLC tissues $(212 / 292,72.60 \%)$ in comparison to corresponding adjacent non-cancerous tissues $(6 / 66,9.09 \%)(p<0.001)$. Clinicopathologic analysis showed that CTHRC1 expression was significantly correlated with differentiation degree $(p<0.001)$, clinical stage $(p<0.001)$, T classification $(p<0.001)$, lymph node metastasis $(p=0.013)$ and distant metastasis $(p<0.001)$. Kaplan-Meier analysis revealed that patients with high CTHRC1 expression had poorer overall survival rates than those with low CTHRC1 expression. Multivariate analysis indicated that CTHRC1 expression was an independent prognostic factor for the overall survival of NSCLC patients. Collectively, CTHRC1 plays important roles in NSCLC progression, and the evaluation of CTHRC1 expression could serve as a potential marker for metastasis progression and prognosis in NSCLC patients.

\section{INTRODUCTION}

Lung cancer is the leading cause of cancer-related mortality worldwide [1] and it is becoming a common malignancy in developing countries such as China because of air pollution and a high cigarette smoking rate [2]. According to pathological classification based on distinct aetiological and morphologic characteristics, lung cancer is divided into small cell lung cancer (SCLC) and nonsmall cell lung cancer (NSCLC). The latter accounts for 
$85 \%$ of all lung cancer patients [3]. Despite advances in developing more efficient surgical techniques and novel chemotherapeutic interventions, the long-term survival rate of NSCLC patients remains poor $[4,5]$. The major cause of extremely poor prognosis in NSCLC patients is mostly attributed to its ability to metastasize to distant organs by complex molecular mechanisms [6]. Furthermore, two-thirds of NSCLC patients present locally advanced or metastatic stage at diagnosis, often leading to death within a few months after diagnosis [7]. Therefore, there is an urgent need to exploit novel molecular markers that can better predict metastasis and prognosis for NSCLC.

Metastasis is the main cause of cancer-related mortality, and it involves a series of steps including invasion and migration, intravasation, circulation in bloodstream, extravasation, colonization growth in specific organs and secondary tumor formation [8]. At the early stage of metastasis, tumor cell mobility and invasive ability relates to loss of intercellular adhesive properties, epithelial-tomesenchymal transition (EMT), proteolytical disruption of the basement membrane and degradation of the extracellular matrix (ECM) [9]. During the early progression of metastasis, activation of the Wnt/ $\beta$-catenin pathway may promote the migration and invasion of cancer cells by upregulating matrix metalloproteinases MMP-7 and MMP-26 and down-regulating cell-cell contact protein E-cadherin [10-13]. However, the molecular mechanisms underlying the aberrant activation of Wnt/ $\beta$-catenin pathway in NSCLC have not been elucidated.

Collagen triple helix repeat containing-1 (CTHRC1) was found to be ubiquitously expressed in numerous cell types such as fibroblasts and smooth muscle cells, and aberrantly up-regulated in several malignant tumors, including melanoma, and cancers of the gastrointestinal tract, breast, thyroid, liver and the pancreas [14-19]. Several reports have documented that cell surface anchored CTHRC1 can stabilize the physical interaction between Wnt ligands and Frizzled receptors, and selectively activate the non-canonical Wnt pathway to regulate cell motility and taxis $[16,20]$. Forced expression of CTHRC1 may contribute to repairing the injured tissue by promoting cell migration and inhibiting the collagen matrix synthesis [21]. In human beings, CTHRC1 shares $92 \%$ of homolog sequences compared to that of the rat [17]. Tang et al [17] reported that CTHRC1 expression was significantly higher in primary invasive and metastatic melanomas but not in benign nevi or non-invasive specimens, and the knockdown of CTHRC1 resulted in a decrease in migration ability in melanoma cancer cells in vitro. Recently, Kharaishvili et al [22] demonstrated that CTHRC1 up-regulation was closely correlated with breast cancer carcinogenesis and bone metastasis. However, currently, little information has addressed the clinical significance of CTHRC1 and the molecular mechanisms by which CTHRC1 promotes the invasion and metastasis of NSCLC.
In this study, we found that CTHRC1 expression was significantly increased in NSCLC cells and surgical tissues, and was closely associated with tumor metastasis. Moreover, knock-down and ectopic expression of CTHRC1 showed that CTHRC1 promoted the invasion and migration of NSCLC cells in vitro via the Wnt/ $\beta$-catenin signaling pathway, and this is further verified by the correlation analysis between CTHRC1 expression and both lymph node and distant metastasis in archived patient samples. Multivariate analysis demonstrated that overexpression of CTHRC1 was an independent prognostic factor for NSCLC patients.

\section{RESULTS}

\section{Elevated expression of CTHRC1 in NSCLC}

To investigate CTHRC1 expression traits in lung cancer, we comparatively analyzed the CTHRC1 protein and mRNA profiles in different lung cancer cell lines and samples. As shown in Figure 1A and B, Western blot and real-time RT-PCR analysis revealed that all lung cancer cell lines, including NCI-H226, NCl-H23, NCl-H820, $\mathrm{NCl}-\mathrm{H} 446$ and A549, exhibited higher levels of CTHRC1 expression compared to that of primary human normal lung epithelial cells (Beas-2Bs) at both the protein and mRNA levels. Furthermore, the fluorescent intensity of CTHRC1 in the five NSCLC cell lines studied was significantly stronger than that of BEAS-2Bs (Fig. 1C). Particularly, its expression was most pronounced in strongly metastatic cell lines (NCI-H226, NCl-H820 and NCl-H446) compared to that of non- or low-metastatic lung cancer cell lines (NCl-H23 and A549) (Fig. 1B). Further comparative analysis demonstrated that CTHRC1 was differentially up-regulated in all eight detected samples paired with corresponding noncancerous tissues from the same patient (Fig. 2A and B), and this was further confirmed by the immunohistochemical results (Fig. 2C). With these findings, our results indicate that CTHRC1 is up-regulated in NSCLC.

\section{CTHRC1 promotes migration and invasion of NSCLC cells in vitro}

To investigate the biological effect of CTHRC1 deregulation on the invasiveness of lung cancer cells, in vitro gain-of-function or loss-of-function analyses were performed using migration and invasion assays. The efficacy of pcDNA3.1-CTHRC1 and CTHRC1-siRNA on CTHRC1 was confirmed by Western blot analysis (Fig. 3A). As shown in Figure 3B, CTHRC1 overexpression drastically strengthened the invasive ability of NCl-H23 cells compared to that of the vector control. Wound healing assay also showed that CTHRC1 overexpression significantly increased the migratory speed of NCl-H23 cells compared to that of the vector control (Fig. 3C). 
A

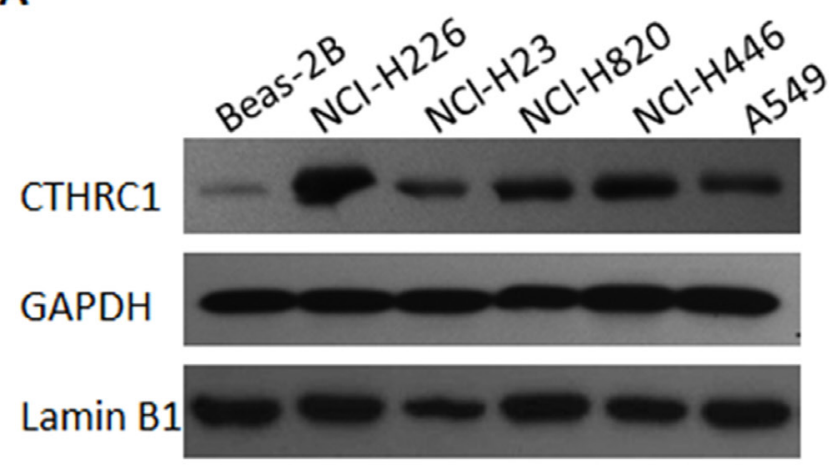

C

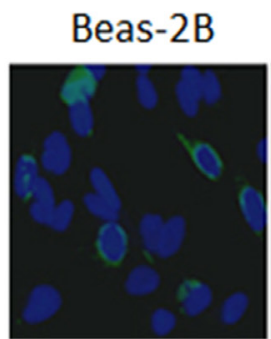

B

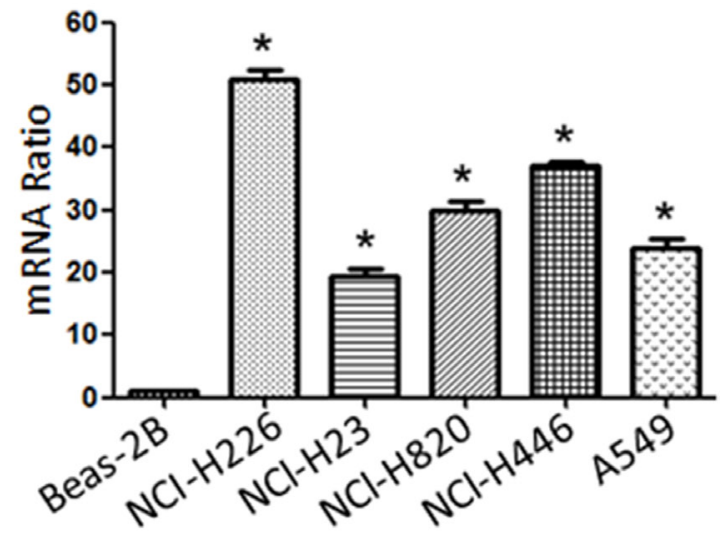

Figure1: Protein and mRNA expression characteristics of CTHRC1 in BEAS-2B and NSCLC cell lines. (A) CTHRC1 protein was detected by Western blot in BEAS-2B and five NSCLC cell lines (NCI-H226, NCl-H23, NCl-H820, NCl-H820 and A549). The GAPDH and Lamin B1 genes were used as internal controls for cytosolic fraction and nuclear fraction, respectively. (B) Real-time PCR analysis of CTHRC1 mRNA levels in BEAS-2B and NSCLC cell lines. Expression intensity of CTHRC1 was normalized for $\beta$-actin. Error bars represent mean $\pm \mathrm{SD}$ from three independent experiments $\left({ }^{*} p<0.05\right)$. (C) Immunofluorescent staining showed that the CTHRC1positive signal was present in the cytoplasm of BEAS-2B and NSCLC cell lines (Original magnification, $\times 400$ ).

In contrast, the silencing of CTHRC1 expression weakened the invasive capability of NCI-H226 cells with a high metastatic phenotype (Fig. 3B and C). Our data indicate that CTHRC 1 contributes greatly to the development of lung cancer metastasis and invasion.

\section{CTHRC1 increases proliferation in lung cancer cells}

In order to examine the role of CTHRC1 in NSCLC cell proliferation, we evaluated the effect of CTHRC1 on NSCLC cell clonogenic assay and cell growth. As shown in Figure 4, up-regulation of CTHRC1 significantly increased colony formation in NCI-H23 cells by $263.46 \%$ compared to that of the control group. Furthermore, cell viability was also enhanced after transfection with pcDNA3.1-CTHRC1. On the contrary, down-regulation of CTHRC1 led to the drastic decline in colony formation and cell viability in NCI-H226 cells.

\section{CTHRC1 mediates NSCLC aggressiveness via

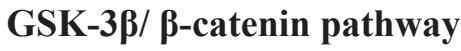

Based on the vital role of the Wnt/ $\beta$-catenin pathway in metastasis, we then explored whether CTHRC1 activates
$\mathrm{Wnt} / \beta$-catenin signaling and if the $\mathrm{Wnt} / \beta$-catenin pathway is involved in CTHRC1-mediated metastasis. In the canonical Wnt/ $\beta$-catenin pathway, the hallmark of Wnt signaling activation is $\beta$-catenin's nuclear translocation, where it forms a complex with a specific T-cell factor/lymphoid enhancer factor (Tcf/Lef) [23]. After up-regulating CTHRC1 expression in NCl-H23 cells with pcDNA3.1CTHRC1, we observed the substantial accumulation of $\beta$-catenin in nucleus, suggesting that CTHRC1 might contribute to the activation of Wnt signaling (Fig. 5A). As expected, luciferase assays also demonstrated that CTHRC1 overexpression significantly increased the transcriptional activity of $\beta$-catenin/TCF in NCl-H23 cells, as determined by the $\beta$-catenin reporter system (TOP/FOP) (Fig. 5B). In contrast, the transfection of CTHRC1-siRNA reduced the $\beta$-catenin/TCF transcriptional activity in $\mathrm{NCl}-\mathrm{H} 226$ cells (Fig. 5B). Also, Western blot analysis revealed that CTHRC1 could promote the phosphorylation of GSK-3 $\beta$ at Ser9 (Fig. 5C). Furthermore, the transcriptional activity of $\beta$-catenin/TCF substantially decreased in CTHRC1expressing cells treated with Wnt/ $\beta$-catenin inhibitor DKK1 and significantly increased in CTHRC1-siRNA- NCI-H226 cells treated with Wnt 5a (Fig. 5D). Also, the number of invasive cells and colonies dramatically decreased when CTHRC1-expressing cells were separately treated with 

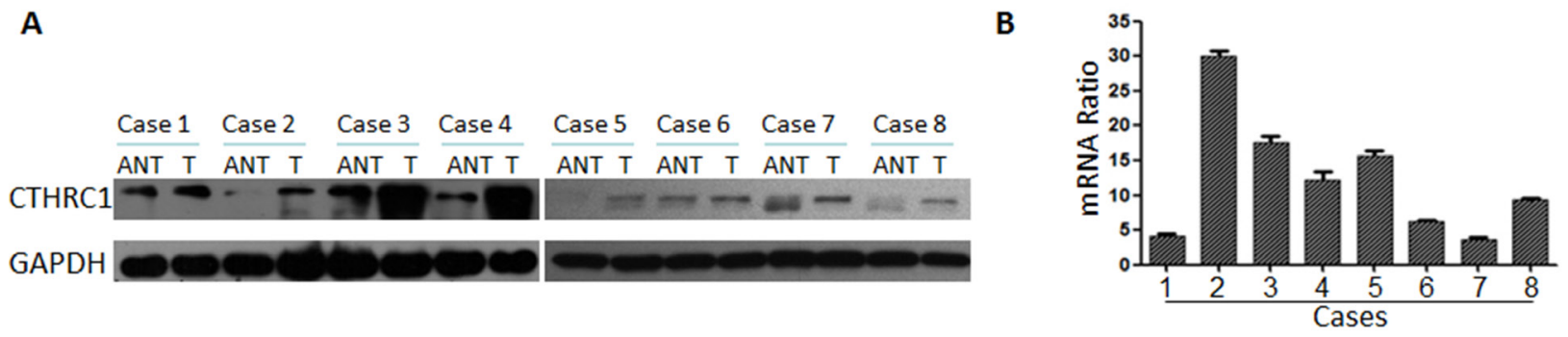

C
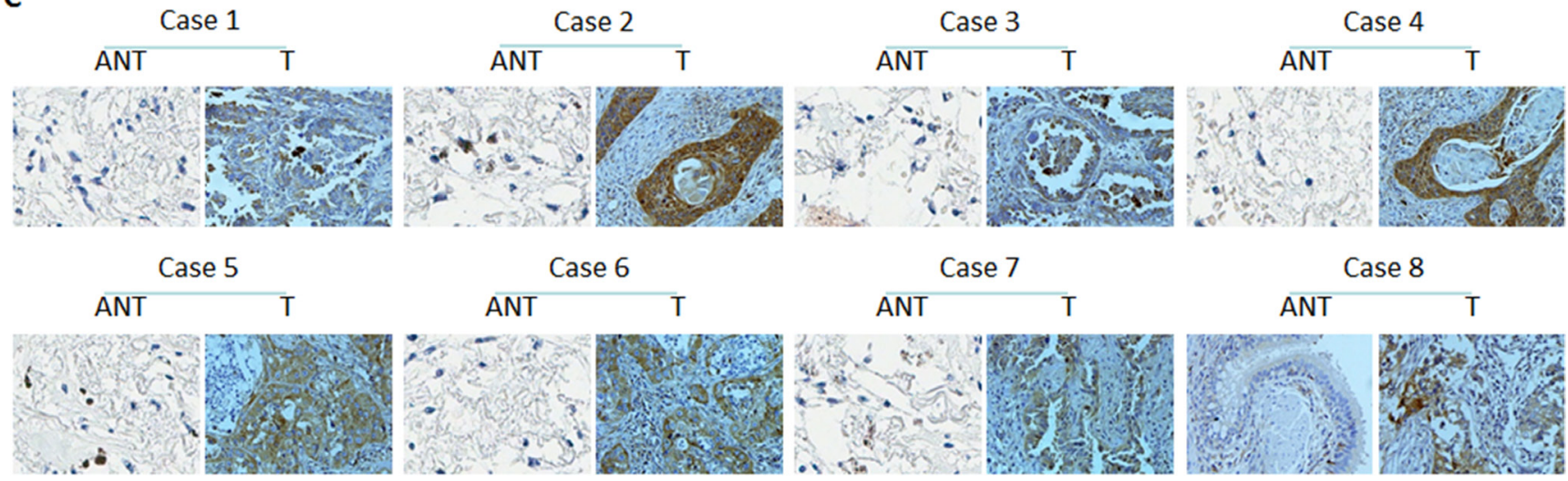

Figure 2: CTHRC1 overexpression in primary NSCLC tissues compared to the corresponding adjacent non-cancerous tissues from the same patient. (A) Western blotting analysis of CTHRC1 expression in each of the primary NSCLC tissue (T) and adjacent non-cancerous tissue (ANT) from the same patient. (B) The average tumor: adjacent non-cancerous tissue (T:ANT) ratios of CTHRC1 expression were quantified by real-time RT-PCR. Expression levels were normalized for $\beta$-actin. Error bars represent mean $\pm \mathrm{SD}$ from three independent experiments $\left({ }^{*} p<0.05\right)$. (C) IHC confirmed that the CTHRC1 protein was significantly elevated in primary NSCLC tissues (T) compared to that of corresponding adjacent non-cancerous tissues (ANT) from the same patient.

DKK1. On the contrary, Wnt5a could increase the invasive ability and colony formation ability in CTHRC1-siRNAtreated cells (Fig. 5E, F).

\section{Association of CTHRC1 overexpression with NSCLC's clinical aggressiveness}

To further elaborate the clinical significance of the above findings in NSCLC, 292 paraffin-embedded NSCLC tissue specimens were selected for CTHRC1 IHC staining. An overview of CTHRC1 expression and clinicopathological parameters is given in Table 1. CTHRC1 expression was significantly up-regulated in primary NSCLC tissues compared to their corresponding adjacent non-cancerous tissues. Semi-quantitative IHC analysis indicated that the MOD values of CTHRC1 staining in primary NSCLC were higher than that of normal lung tissues. CTHRC1 staining intensity gradually increased in accordance with the clinical stages from I to IV ( $p<0.001$, Fig. $6 \mathrm{~A}$ and B). And this was further confirmed by the Real-time PCR results (Fig. 6C). Furthermore, statistical analysis exhibited that high CTHRC1 expression was strongly correlated with the differentiation degree $(p<0.001)$, clinical stage $(p<0.001)$, T classification $(p<0.001)$, lymph node metastasis $(p=0.013)$ and distant metastasis $(p<0.001)$ of patients with NSCLC, and this was further verified by the Spearman correlation analysis (Table 2). In contrast, there were no significant correlations between CTHRC1 high expression and age or gender. These data support the hypothesis that CTHRC1 is involved in the regulation of NSCLC's invasive ability.

\section{CTHRC1 expression is closely correlated with poor overall survival time}

To investigate the prognostic significance of high CTHRC1 expression in patients with NSCLC, the Kaplan-Meier method was used to evaluate the correlation between high CTHRC1 expression and the survival curve. Both the Kaplan-Meier method and the log-rank test revealed a significantly inverse correlation between high CTHRC1 expression level and patient survival ( $p<0.001$ ), clearly disclosing that higher levels of CTHRC1 expression were associated with shorter survival rate (Fig. 7A). In both the squamous cell carcinoma group and adenocarcinoma group, patients with high CTHRC1 expression showed a shorter survival time in comparison to those with low CTHRC1 expression ( $p<0.001$, Fig. 7B and C). Also, univariate and multivariate Cox regression analysis demonstrated that CTHRC1 expression level was an independent prognostic marker for NSCLC (Table 3). Thus, present data suggest that CTHRC1 may be a valuable biomarker for predicting the prognosis of NSCLC patients. 
A

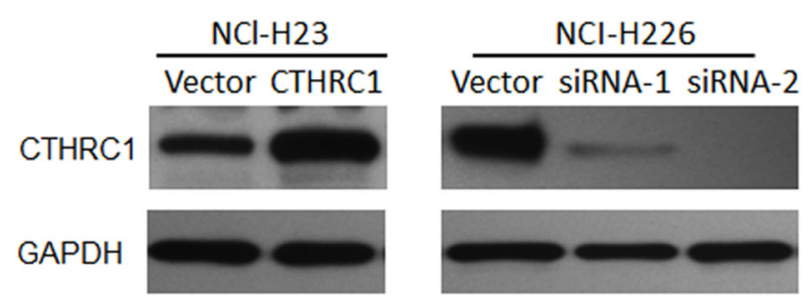

B
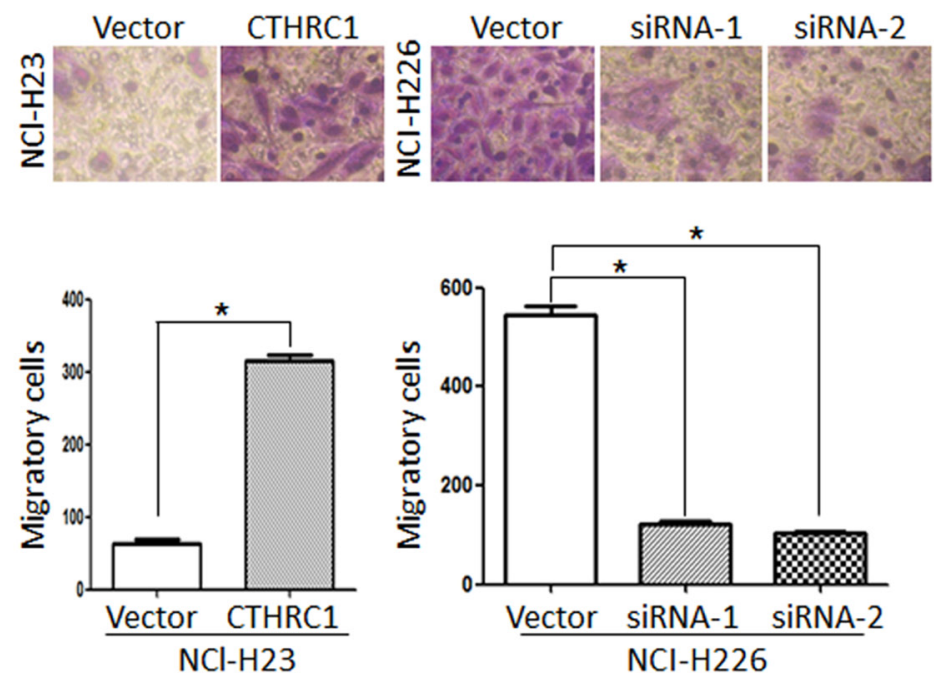

C
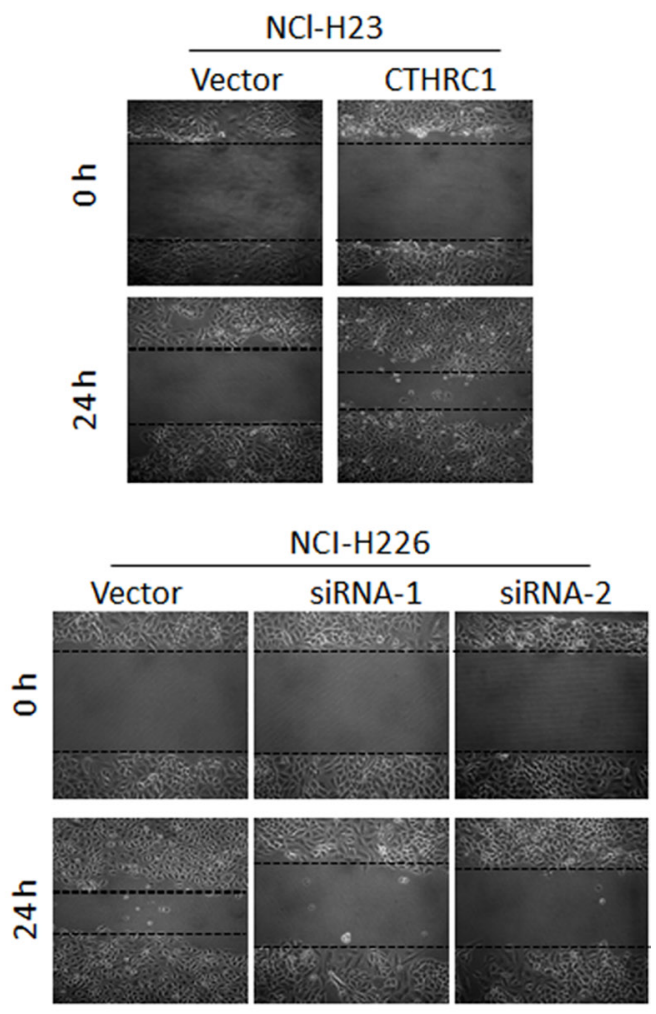

Figure 3: Aberrant expression of CTHRC1 promotes the invasion and migration of NSCLC cells in vitro. (A) NCl-H23 and NCl-H226 cells were transfected with pcDNA3.1-CTHRC1 and CTHRC1-siRNA, respectively. CTHRC1 protein expression was analyzed by using the Western blot method. GAPDH was employed as an inner control. (B) The effect of CTHRC1 expression changes on the invasive ability in indicated cells was detected by Matrigel invasion assay. (Upper) Cells that adhered to the lower surface of the filtered were stained with hematoxylin. (Down) The number of migrated cells was from three independent experiments. (C) The migratory speed of CTHRC1-expressing NCl-H23 cells and CTHRC1-siRNA-expressing NCl-H226 cells was monitored through a scratch wound assay at different times. The representative images are from three independent experiments.

\section{DISCUSSION}

Despite the recent advancement in therapeutic options, finding an accurate and efficient treatment option to monitor the progression of lung cancer still remains a challenge. One reason is the complex molecular mechanisms involved in the carcinogenesis and progression of lung cancer [24]. Therefore, elucidation of the exact molecular pathway involved in the pathogenesis of lung cancer will greatly contribute towards improving the outcome for patients. CTHRC1 is a secreted glycosylated protein that contains a NH2terminal signaling peptide for extracellular secretion, a short collagen triple helix repeat of 36 amino acids, and a $\mathrm{COOH}$-terminal globular domain [21]. Aberrant overexpression of CTHRC1 has been observed in several kinds of malignant tumors including breast cancer, gastric cancer and melanoma [17]. In the present study, our data demonstrated that CTHRC1 expression was up-regulated in human NSCLC tissues and cultured
NSCLC cells compared to that of corresponding adjacent non-cancerous tissues and normal lung epithelial cells. Furthermore, high CTHRC1 expression was strongly correlated with the clinical stages, lymph node metastasis and distant metastasis. We also found that the CTHRC1 protein expression level in NCI-H226 cells with high metastatic ability was higher than that in NCl-H23 cells with low metastatic ability, and these results were further confirmed by real-time PCR and immunofluorescence assays. Multivariate analysis suggested that CTHRC1 may be an independent biomarker that can be used for NSCLC prognosis. Collectively, our results indicate that CTHRC1 is closely associated with tumor aggressiveness and may represent an independent prognostic biomarker for NSCLC patients.

Collected evidence supports the idea that CTHRC1 is closely linked with tumor invasion as well as metastasis [17, 25-28]. Using immunohistochemistry staining, Tang and Dai et al [17] found that CTHRC1 expression is absent in the benign nevi or noninvasive 
A
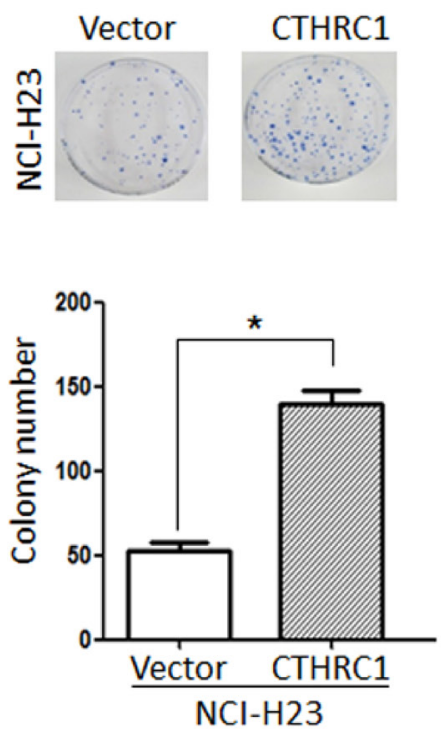
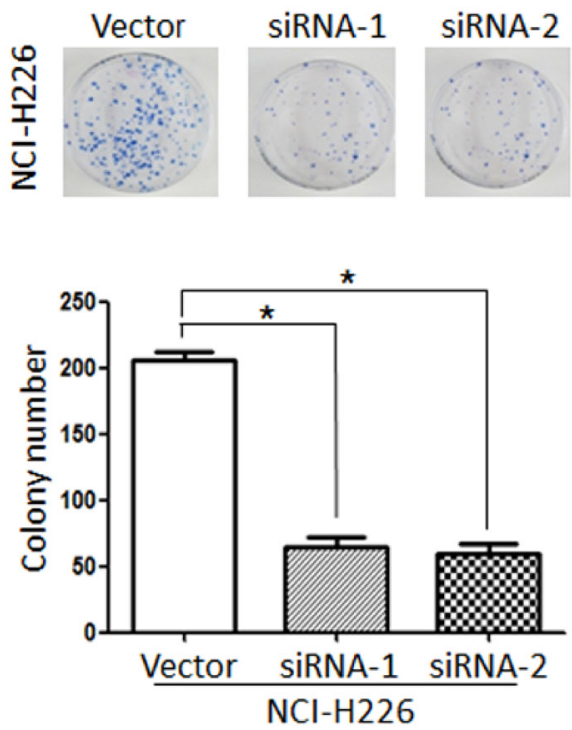

B
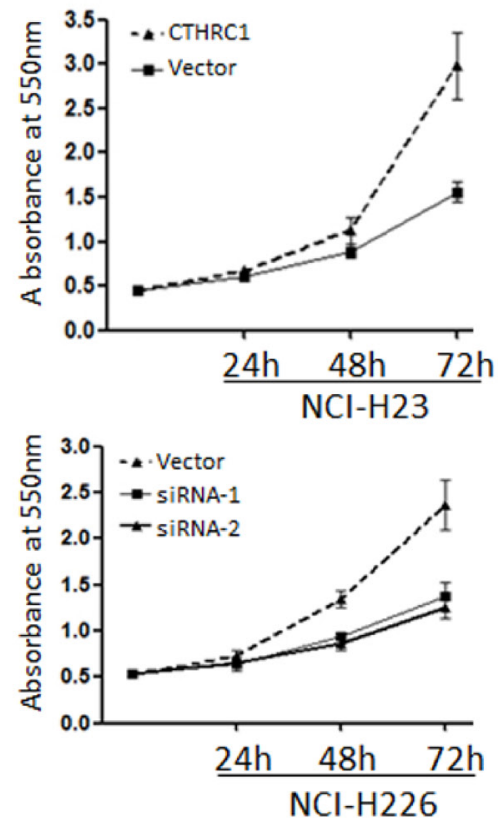

Figure 4: Effect on the soft agar colony formation and proliferation ability of NSCLC cells following CTHRC1 ectopic expression. (A) Colony forming ability of $\mathrm{NCl}-\mathrm{H} 23$ cells transfected with pcDNA3.1-CTHRC1 and NCl-H226 transfected with CTHRC1-siRNA. Data are mean \pm SD of three independent transfections. (B) Effect of CTHRC1 on NSCLC cell growth was evaluated by MTT assay. The line charts showed the relative MTT absorbance, which indicated the cellular viability.

stages of melanoma (melanoma in situ) and dramatically increases in the invasive and metastatic melanoma. They demonstrated that the migratory behaviors of KZ-28 melanoma cells are inhibited by the specific CTHRC1 siRNA oligos. In addition, up-regulation of CTHRC1 resulted in an elevated invasion of colon cancer cells, but this process is significantly reduced by siRNA-mediated CTHRC1 knockdown [25]. Recently, Ma et al [26] further elucidated the role of CTHRC1 as a vital regulator of invasion and metastasis in the tumor microenvironment and documented that CTHRC1 overexpression greatly increases the likelihood of the aggressive feature in GIST patient. These studies suggest that CTHRC1 plays vital roles in the metastasis of malignant tumors; however, how it induces these phenotypes has remained unclear.

To further elucidate the biological roles of CTHRC1 as a putative oncogene, we examined the effect of CTHRC1 on cell proliferation and invasiveness in NSCLC cells using both gain of function and loss of function approaches. Since CTHRC1 participates in tissue remodeling in rheumatoid arthritis and injured arteries [21], we speculated that CTHRC1 may have a similar function in promoting NSCLC cell proliferation. In this study, up-regulation of CTHRC1 strongly enhanced the proliferation ability of NSCLC cells. Conversely, knockdown of endogenous CTHRC1 significantly reduced cell proliferation properties of NSCLC cells. Using cell migration assay, Pyagay et al demonstrated that elevated CTHRC1 levels enhance the migratory ability of fibroblasts and smooth muscle cells [21]. Turashvili et al showed that CTHRC1 was overexpressed in invasive lobular breast carcinoma compared to normal ductal and lobular cells [18]. In the present study, we have found that deregulation of CTHRC1 drove cell migration and promoted NSCLC cells to spread. Furthermore, CTHRC1's effect on promoting the aggressiveness of NSCLC cells was verified by IHC results on the significant correlations between CTHRC1 expression and lymph node metastasis or distant metastasis in NSCLC patients. Based on the above findings, CTHRC1 was thought to be an invasion-promoting protein and eventually contributed to NSCLC pathogenesis and metastasis. However, further exploration is needed to explain how CTHRC1 regulates cancer migration and invasiveness.

Next, to further elucidate the molecular mechanism of how CTHRC1 mediates the migration of NSCLC cells, we analyzed its effects on the Wnt/ $\beta$-catenin signaling cascade. Tamamoto et al demonstrated that CTHRC1 activates the non-canonical Wnt/PCP signaling by forming complexes with the Wnt-Fzd and also inhibits the canonical pathway in mouse cochlear sensory hair cells [20]. To our knowledge, the binding of Wnts to Frizzled (Fzd) receptors plays an important role in many Wnt-mediated events [29]. Moreover, in most settings, the canonical Wnt/ $\beta$-catenin signaling pathway has been extensively implicated as the regulator of tumor cell invasion and metastasis [30-32]. $\beta$-catenin is a main downstream effector of the canonical Wnt pathway. And it is recruited to the phosphorylation/destruction complex in the absence of Wnt ligands [33]. Overexpression of 
A

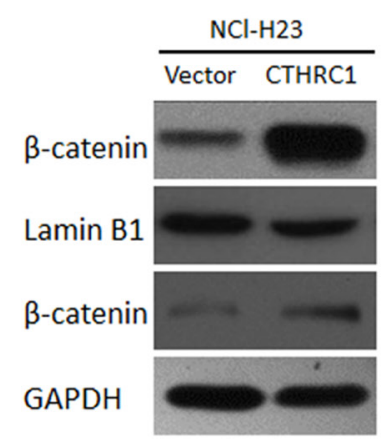

B
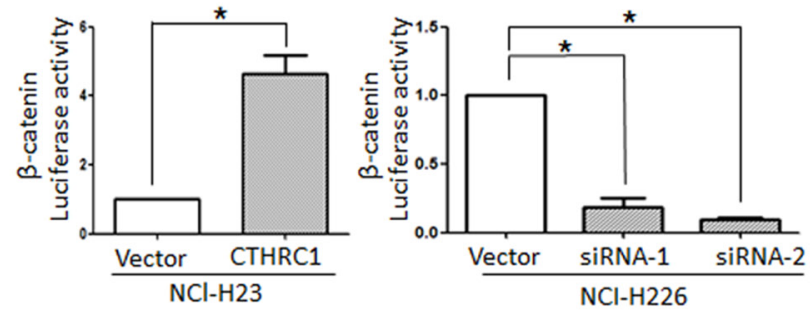

C

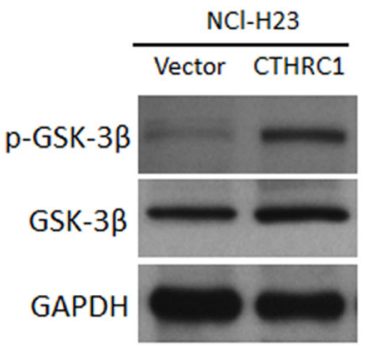

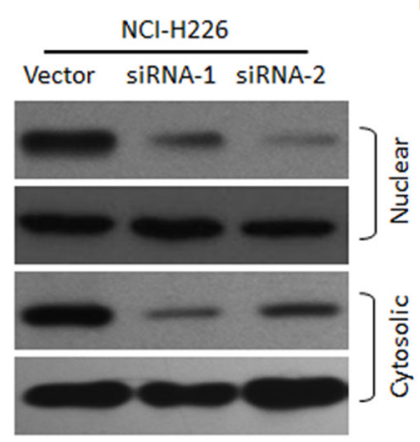

D
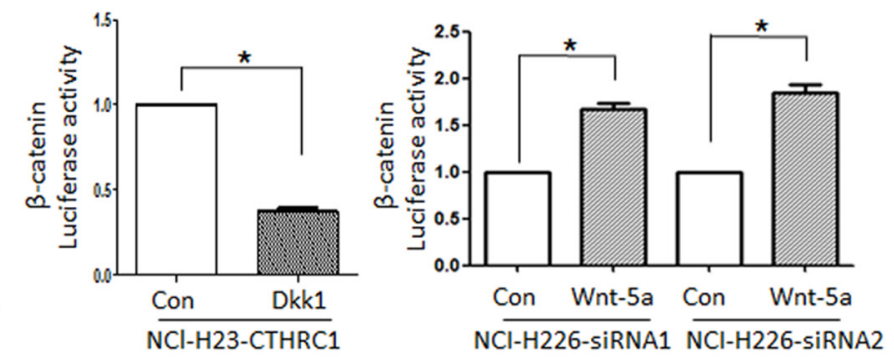

E
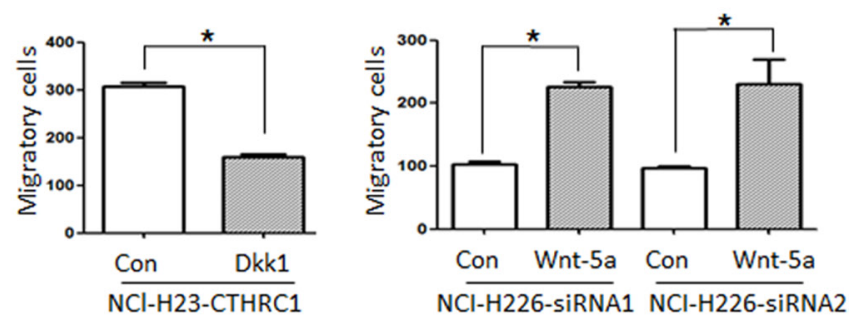

$\mathbf{F}$
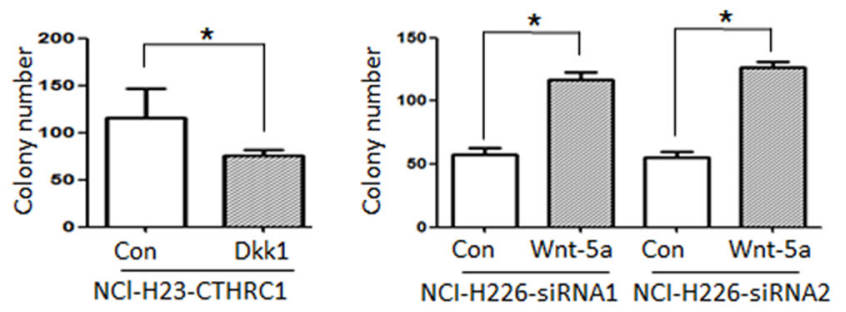

Figure 5: CTHRC1 promotes aggressiveness of NSCLC via activating Wnt/ $\boldsymbol{\beta}$-catenin pathway. (A) CTHRC1 induces $\beta$-catenin nuclear translocation. The subcellular localization of $\beta$-catenin was observed through Western blot. (B) CTHRC1 enhances $\beta$-catenin/TCF transcriptional activity, which was evaluated by the TCF-responsive promoter reporter (TOP-flash) or nonresponsive control reporter (FOP-flash); The luciferase activity was measured as the ratio of TOP/ FOP. Relative luciferase activity is presented as the mean \pm SD from each sample after normalizing to the control. The asterisk indicates statistical significance $(p<0.01)$. (C) The Ser-9 phosphorylation level of GSK-3 $\beta$ was modulated by CTHRC1 in NSCLC cells. (D), (E) and (F). Dkk1 (Wnt/ $\beta$-catenin inhibitor) decreased CTHRC1-mediated $\beta$-catenin/TCF transcriptional activity (D), migration (E) and proliferation ability (F). On the contrary, Wnt-5a increased CTHRC1-siRNA-mediated $\beta$-catenin/TCF transcriptional activity (D), migration (E) and proliferation ability (F).

CTHRC1 led to a significant increase in Wnt/ß-catenin transcriptional activity and an accumulation of nuclear $\beta$-catenin. Moreover, we found that treatment with DKK1, a specific inhibitor of $\mathrm{Wnt} / \beta$-catenin signaling, diminished the migration ability and activity of Wnt/ $\beta$-catenin signaling in NSCLC cells induced by CTHRC1 overexpression. In addition, Wnt-5a could reverse CTHRC1-siRNA's effect on Wnt/ $\beta$-catenin activity in NSCLC cells. These results suggest that CTHRC1-induced activation of $\mathrm{Wnt} / \beta$-catenin signaling may account for its effect on cell proliferation and motility. GSK-3 $\beta$, a multifunctional kinase of cancer, is constitutively activated because of tyrosine-216 phosphorylation, resulting in the phosphorylation of $\beta$-catenin [33]. Conversely, the phosphorylation of serine- 9 deactivates GSK $3 \beta$, inhibiting the proteasomal degradation of $\beta$-catenin [34-37]. Our preliminary studies also revealed that Ser-9 phosphorylation of GSK-3 $\beta$ was involved in the stability and transcriptional activity of CTHRC1-mediated $\beta$-catenin. On the basis of these results, we speculate that CTHRC1 promotes cell proliferation and migration via activation of the $\mathrm{Wnt} / \beta$-catenin pathway. However, the detailed molecular mechanism regarding how CTHRC1 activates the $\mathrm{Wnt} / \beta$-catenin pathway needs to be further explored.

In summary, we found that CTHRC1 may serve as a novel biomarker for NSCLC patients. The molecular mechanisms governing the role of CTHRC1 in NSCLC cell aggressiveness is mediated through the regulation of the Wnt/ $\beta$-catenin pathway. Finally, CTHRC1 
Table 1: Correlation between CTHRC1 expression and clinicopathologic characteristics of NSCLC

\begin{tabular}{|c|c|c|c|}
\hline \multirow{2}{*}{ Characteristics } & \multicolumn{2}{|c|}{ CTHRC1 expression } & \multirow{2}{*}{$\frac{\text { Chi-square test }}{p \text {-value }}$} \\
\hline & High expression & Low expression & \\
\hline Normal lung tissues & 6 & 66 & $<0.001$ \\
\hline NSCLC tissues & 212 & 80 & \\
\hline Age(years) & & & 0.584 \\
\hline$\leq 50$ & 68 & 23 & \\
\hline$>50$ & 144 & 57 & \\
\hline Gender & & & 0.282 \\
\hline Male & 151 & 62 & \\
\hline Female & 61 & 18 & \\
\hline Smoking & & & $<0.001$ \\
\hline Yes & 168 & 21 & \\
\hline No & 44 & 59 & \\
\hline Clinical stage & & & $<0.001$ \\
\hline I & 20 & 33 & \\
\hline II & 102 & 41 & \\
\hline III & 52 & 5 & \\
\hline IV & 38 & 1 & \\
\hline T Classification & & & $<0.001$ \\
\hline $\mathrm{T} 1$ & 62 & 45 & \\
\hline $\mathrm{T} 2$ & 74 & 21 & \\
\hline $\mathrm{T} 3$ & 57 & 12 & \\
\hline $\mathrm{T} 4$ & 19 & 2 & \\
\hline N Classification & & & 0.097 \\
\hline N0 & 106 & 53 & \\
\hline N1 & 78 & 20 & \\
\hline $\mathrm{N} 2$ & 15 & 4 & \\
\hline N3 & 13 & 3 & \\
\hline Lymph node metastasis & & & 0.013 \\
\hline N0 & 106 & 53 & \\
\hline N1-3 & 106 & 27 & \\
\hline M Classification & & & $<0.001$ \\
\hline M0 & 174 & 79 & \\
\hline M1 & 38 & 1 & \\
\hline EGFR mutation & & & 0.562 \\
\hline Positive & 29 & 17 & \\
\hline Negative & 35 & 16 & \\
\hline K-ras mutation & & & 0.711 \\
\hline Positive & 9 & 5 & \\
\hline Negative & 49 & 34 & \\
\hline
\end{tabular}


A

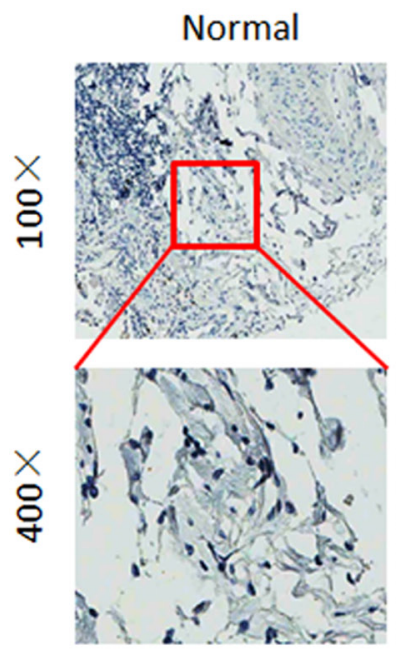

B

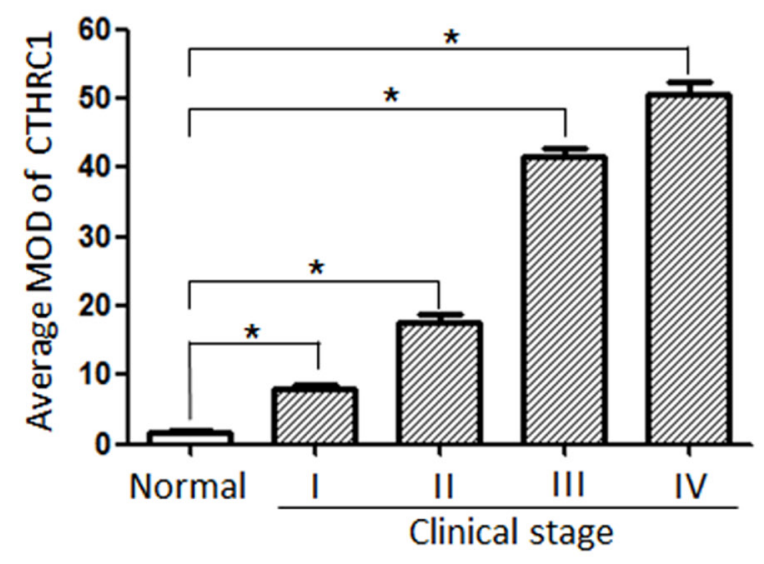

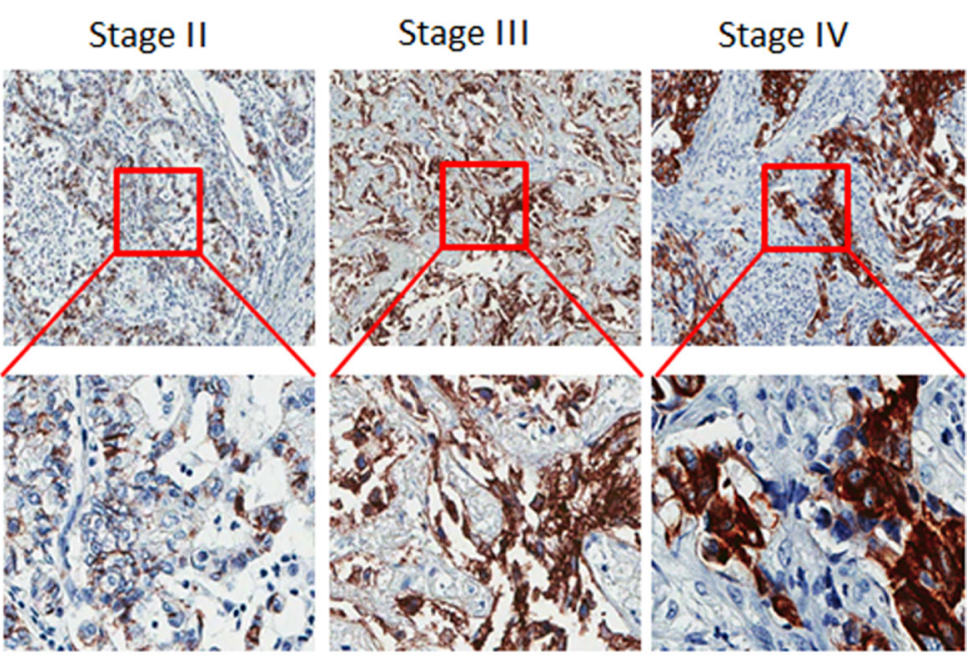

C

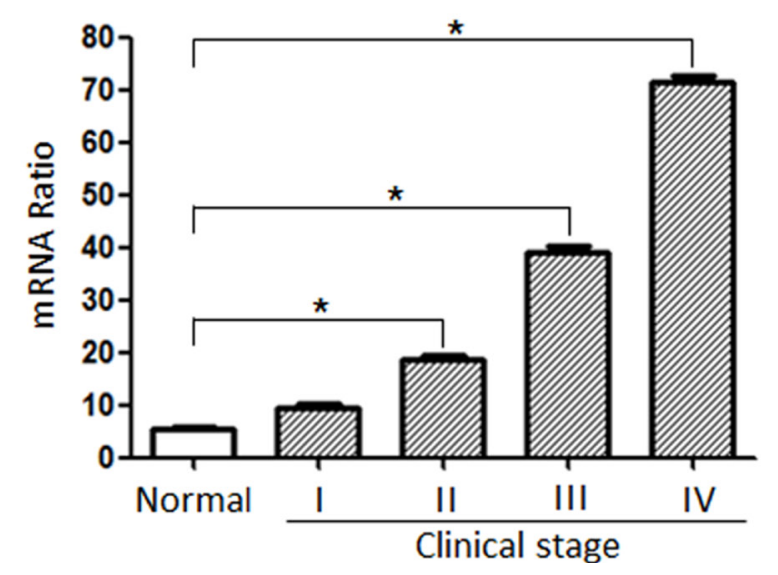

Figure 6: CTHRC1 protein and mRNA overexpression characteristics in archived paraffin-embedded NSCLC tissues from different clinical stages. (A) CTHRC1 staining intensity gradually increased in accordance with the clinical stages from I to IV by IHC. Representative images from IHC analyses of CTHRC1 expression in normal lung tissues and primary NSCLC tissues. (B) Statistical analyses for the average MOD of CTHRC1 staining between normal lung tissues (72 cases) and NSCLC tissues of different clinical stages $\left({ }^{*} p<0.05\right)$. (C) CTHRC1 mRNA expression levels between normal lung tissues (72 cases) and NSCLC tissues of different clinical stages $(* p<0.05)$.

could be established as a potential target in NSCLC treatment, because its overexpression induces NSCLC aggressiveness.

\section{MATERIALS AND METHODS}

\section{Cell lines}

Primary normal lung epithelial cells (BEAS-2B) were purchased from American Type Culture Collection (ATCC) and cultured in a keratinocyte serum-free medium (Invitrogen, Carlsbad, CA) supplemented with epidermal growth factor (EGF) (Invitrogen), bovine pituitary extract, and antibiotics $(100 \mu \mathrm{g} / \mathrm{mL}$ streptomycin and $100 \mathrm{U} / \mathrm{mL}$ penicillin). Lung cancer cell lines, including NCI-H226, NCl-H23, NCl-H820, NCl-H446, and
A549, were maintained in Dulbecco's modified Eagle's medium (DMEM; Invitrogen, USA) supplemented with $10 \%$ fetal bovine serum (HyClone, Logan, UT). CTHRC1 overexpression plasmid pcDNA3.1-CTHRC1 and CTHRC1 siRNA (RiboBio, China) were transiently transfected using Lipofectamine 2000 (Invitrogen, USA).

\section{Tissue specimen selection}

A total of 292"lung cancer" cases from 2000 to 2011 were chosen from the surgical pathology archives of the Affiliated First Hospital, Sun Yat-sen University. The age of these selected patients at the time of surgery ranged from 31 to 83 years (mean, 58.5 years). A follow-up was conducted by using hospital medical records and a telephone interview. According to the criteria of the 
Table 2: Spearman correlation analysis between CTHRC1 and clinicopathologic parameters

CTHRC1 expression level

\begin{tabular}{|l|c|c|}
\cline { 2 - 3 } \multicolumn{2}{c}{} & \multicolumn{2}{c}{ Correlation coefficient } & $\boldsymbol{p}$-value \\
\hline Differentiation degree & 0.397 & $<0.001$ \\
\hline Clinical stage & 0.262 & $<0.001$ \\
\hline T Classification & 0.254 & $<0.001$ \\
\hline N Classification & 0.141 & 0.016 \\
\hline M Classification & 0.219 & $<0.001$ \\
\hline Lymph node metastasis & 0.146 & 0.013 \\
\hline
\end{tabular}

A

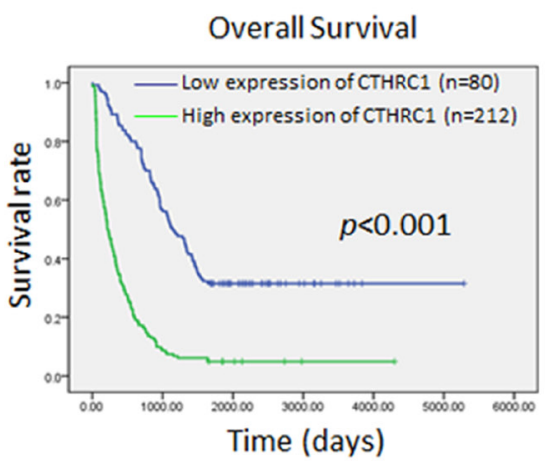

B

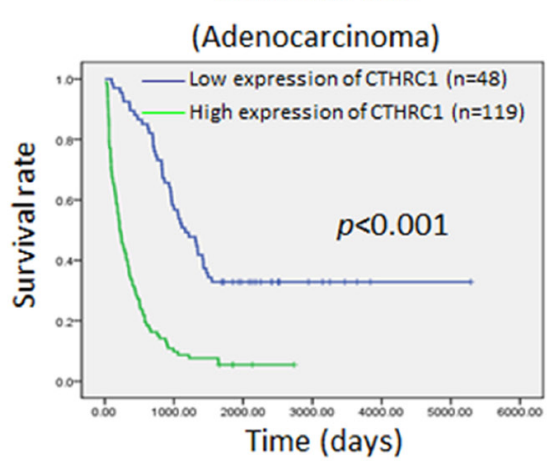

C

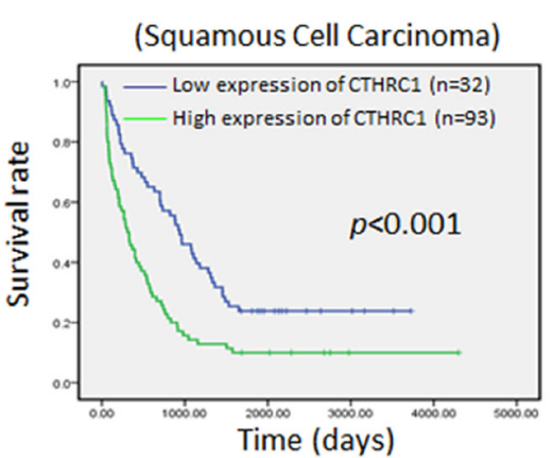

Figure 7: Kaplan-Meier survival analyses for NSCLC patients with low CTHRC1 expression versus high CTHRC1 expression. (A) The cumulative overall survival differences between patients with high and low CTHRC1 expression. (B) and (C) Statistical significance of the difference between curves of CTHRC1 high-expressing and low-expressing patients was compared in adenocarcinoma (B) and squamous cell carcinoma (C) patient subgroups. P values were calculated according to the log-rank test.

World Health Organization (2004), the 292 cases were divided into 125 squamous cell carcinomas and 167 adenocarcinomas. Among the 292 cases with NSCLC, 72 cases contained primary carcinoma and corresponding normal lung tissue (Table 4). Another 97 NSCLC cases with EGFR (exons 18, 19, 20 and 21) and K-ras (condons 12 and 13) mutation information were obtained from November 2009 to May 2011. These 97 NSCLC cases were not detected to include T790M mutation in exon 20 before receiving radiotherapy or chemotherapy. Furthermore, eight pairs of fresh primary NSCLC tissues and adjacent non-cancerous lung tissues obtained from patients were used for real-time RT-PCR and Western blot. The medical ethics committee of Sun Yat-sen University approved the present retrieval method of cancer specimens.

\section{Immunohistochemical staining and evaluation}

Sections $(4 \mu \mathrm{m})$ of formalin-fixed, paraffinembedded tissues were made by using a rotary microtome (Leica, Wetzlar, Germany) and labeled with antiCTHRC1 (rabbit polyclonal antibody, 1:1,000 dilution;
Abcam (ab85739), USA). 3,3'-Diaminobenzidine tetrahydrochloride was added to visualize the staining reaction, followed by counterstaining with Mayer hematoxylin. The number of immunopositive cells was semiquantitatively estimated. First, staining intensity was scored: colorless (0), buff (1), brownish yellow (2), and dark brown (3). Second, the percentage of positive cells was scored: no positive cells ( 0 ), $10 \%$ positive cells or less (1), $11 \%$ to $50 \%$ positive cells (2), $51 \%$ to $75 \%$ positive cells (3), and more than $75 \%$ positive cells (4). The staining index was obtained by multiplying staining intensity score to the positive tumor cell score. The cutoff value for CTHRC1 was chosen based on a measure of heterogeneity using the log-rank test statistical analysis with respect to overall survival. An optimal cutoff value was identified: a staining index of four or greater was used to define tumors of high expression, and three or lower for low expression. A known positive control (human skin melanoma) and a negative control (an antibody dilution solution or an irrelevant rabbit IgG of the same isotype) were included with each run of staining to monitor batch consistency. The staining index was calculated using the Aperio ImageScope software (Aperio Technologies). 
Table 3: Univariate and multivariate statistical analyses for various prognostic parameters in patients with NSCLC

\begin{tabular}{|c|c|c|c|c|c|c|}
\hline \multirow[b]{2}{*}{ Characteristics } & \multirow[b]{2}{*}{ No } & \multicolumn{2}{|c|}{ Univariate analysis } & \multicolumn{3}{|c|}{ Multivariate analysis } \\
\hline & & $p$-value & $\begin{array}{c}\text { Regression } \\
\text { coefficient (SE) }\end{array}$ & $p$-value & Relative risk & $95 \% \mathrm{CI}$ \\
\hline $\begin{array}{l}\text { Expression of } \\
\text { CTHRC1 }\end{array}$ & & $<0.001$ & $0.378(0.126)$ & $<0.001$ & 1.713 & $1.003-3.217$ \\
\hline Low expression & 80 & & & & & \\
\hline High expression & 212 & & & & & \\
\hline $\begin{array}{l}\text { Differentiation } \\
\text { degree }\end{array}$ & & $<0.001$ & $0.367(0.121)$ & 0.017 & 1.618 & $1.121-2.329$ \\
\hline Well & 79 & & & & & \\
\hline Moderately & 141 & & & & & \\
\hline Poorly & 72 & & & & & \\
\hline Clinical stage & & $<0.001$ & $0.394(0.132)$ & $<0.001$ & 1.517 & $1.127-1.798$ \\
\hline $\mathrm{I}$ & 93 & & & & & \\
\hline II & 103 & & & & & \\
\hline III & 57 & & & & & \\
\hline IV & 39 & & & & & \\
\hline T Classification & & $<0.001$ & $0.467(0.223)$ & 0.008 & 1.61 & $1.097-2.274$ \\
\hline $\mathrm{T} 1$ & 107 & & & & & \\
\hline $\mathrm{T} 2$ & 95 & & & & & \\
\hline T3 & 69 & & & & & \\
\hline $\mathrm{T} 4$ & 21 & & & & & \\
\hline N Classification & & $<0.001$ & $0.402(0.195)$ & 0.003 & 1.609 & $1.105-2.319$ \\
\hline No & 159 & & & & & \\
\hline N1 & 98 & & & & & \\
\hline $\mathrm{N} 2$ & 19 & & & & & \\
\hline N3 & 16 & & & & & \\
\hline
\end{tabular}

To attain consistencies in IHC staining intensities, the mean optical density (MOD) was utilized to score the staining intensity of each slide. Five representative fields from each case were randomly selected to determine the MOD, representing the concentration of the stain or proportion of positive pixels within the whole tissue.

\section{Western blot and immunofluorescence}

Tissue or cell lysates were prepared in radioimmunoprecipitation assay (RIPA) buffer. Immunoblot analyses were performed as earlier [23]. Blotted membranes were incubated with the antibodies for CTHRC1 (Abcam, Ltd., USA), $\beta$-catenin, p-GSK-3 $\beta$ (Ser-9), GSK-3 $\beta$, GAPDH and LaminB1 (Abcam, Cambridge, UK) in $5 \% \mathrm{milk} / \mathrm{TBST}$ (tris-buffered saline Tween-20), and then with horseradish peroxidase (HRP)-conjugated secondary antibodies (Santa Cruz Biotechnology). Immunoreactive bands were observed by using a chemiluminescent substrate. For the immunofluorescence assay, cells cultured in the chamber slides were probed with CTHRC1. The fluorescein isothiocyanate (FITC)-conjugated anti-IgG was purchased from Molecular Probes. Cells were observed through an Olympus BX51 fluorescence microscope (Olympus, Tokyo, Japan). 
Table 4: Clinicopathologic characteristics of patients with NSCLC

\begin{tabular}{|l|l|l|l|}
\hline \multicolumn{2}{|l}{ All cases (\%) } & Gender & \\
\hline Age(years) & & Male & $213(72.95)$ \\
\hline$\leq 50$ & $91(31.16)$ & Female & $79(27.06)$ \\
\hline Differentiation degree & $201(68.84)$ & Clinical stage & \\
\hline Well & $79(27.06)$ & I & $93(31.85)$ \\
\hline Moderately & $141(48.29)$ & II & $103(35.27)$ \\
\hline Poorly & $72(24.66)$ & III & $57(19.52)$ \\
\hline & & IV & $39(13.36)$ \\
\hline T Classification & & N Classification & \\
\hline T1 & $107(36.64)$ & N0 & $159(54.45)$ \\
\hline T2 & $95(32.53)$ & N1 & $98(33.56)$ \\
\hline T3 & $69(23.63)$ & N2 & $19(6.51)$ \\
\hline T4 & $21(7.19)$ & N3 & $16(5.48)$ \\
\hline Distant metastasis & & Smoking & \\
\hline M0 & $253(86.64)$ & Yes & $189(64.73)$ \\
\hline M1 & $39(13.36)$ & No & $103(35.27)$ \\
\hline Vital status (at follow-up) & & Expression level of CTHRC1 & \\
\hline Alive & $37(12.67)$ & Low expression & $80(27.40)$ \\
\hline Death & $255(87.33)$ & High expression & $212(72.60)$ \\
\hline EGFR mutation & & K-ras mutation & $14(14.43)$ \\
\hline Positive & $46(47.42)$ & Positive & $83(85.57)$ \\
\hline Negative & $51(52.58)$ & Negative & \\
\hline
\end{tabular}

\section{Total RNA extraction and Real-time RT-PCR}

Total RNA was prepared from tissue specimens using the RNAeasy kit (Qiagen, USA). The amplification was carried out in a total volume of $20 \mu \mathrm{L}$ containing LightCycler FastStart DNA Master SYBR green I (Roche, USA). Ct value (initial amplification cycle) of each standard dilution was plotted against standard cDNA copy numbers. By using the standard curves for each gene, the sample cDNA copy number was calculated according to the sample Ct value. Standard curves and PCR results were analyzed using ABI7000 software (Applied Biosystems, Foster City, CA, USA). Primers were CTHRC1: (sense) 5'-TGG ACA CCC AAC TAC AAG CA-3' and (antisense) 5'-GAA CAA GTG CCA ACC CAG AT-3'. $\beta$-actin (primers: sense 5'-GCA TGG GTC AGA AGG ATT CCT-3', antisense 5'- TCG TCC CAG TTG GTG ACG AT-3') was used as an internal reference.

\section{Scratch wound assay}

NSCLC cells transfected with vector control, CTHRC1 or CTHRC1 siRNA were plated in a 24-well plate and incubated under permissive conditions. After $90 \%$ confluence, the confluent cell monolayer was scratched using a $1-\mathrm{mL}$ pipette tip to obtain a 'wounded' linear. Then, the cells were incubated in a serum-free medium for 48 hours. Cell migration was observed at different times and photos were taken under an inverted microscope.

\section{Transwell matrix penetration assay}

The invasive ability was measured by using 24-well BioCoat cell culture inserts (Costar, New York, NY, USA) with 8 - $\mu$ m-porosity polyethylene terephthalate membranes coated with Matrigel Basement Membrane Matrix (Cultrex, MD, USA). $4 \times 10^{4}$ lung cancer cells 
transfected with vector, CTHRC1 or CTHRC1 siRNA were then added to the upper chamber of the BioCoat cell culture inserts, and the medium containing serum (10\%) was utilized as the chemoattractant in the lower chamber. At the end of the assay, the cells that did not migrate or invade the pores were removed with a cotton swab. After fixing with $1 \%$ paraformaldehyde and staining with hematoxylin, cells adhering to the lower membrane of the inserts were counted and observed under an IX71 inverted microscope (Olympus Corp, Tokyo, Japan). Cell counts are expressed as the average number of cells per field of view. Three independent experiments were performed and the data are presented as the average \pm standard deviation.

\section{Colony formation assay}

After 48 hours of transfection, lung cancer cells transfected with vector, pcDNA3.1-CTHRC1 or CTHRC1 siRNA were trypsinized, counted, and seeded in $60 \mathrm{~mm}$ dishes at 200 cells per dish. The medium was changed every four days. After two weeks of incubation under the conditions of $37^{\circ} \mathrm{C}$ and $5 \% \mathrm{CO} 2$, colonies were fixed with acetic acid-methanol (1:4) and stained with crystal violet prior to being counted. Colonies containing more than 50 cells were counted under a microscope.

\section{Cell viability assay}

Cell viability assays were performed according to the following method. In the 96-well plates, the logarithmically growing cells such as NCI-H23 and NCI-H226 $(1 \times 105 / \mathrm{L})$ were seeded in each well at $150 \mu \mathrm{L} /$ well 24 hours before transfection. $20 \mu \mathrm{L}$ of filter-sterilized 3-(4,5-Dimethylthiazol-2-yl)-2, 5-diphenyltetrazolium bromide (MTT, $10 \mathrm{mg} / \mathrm{mL}$ ) was dissolved in PBS and added to each well, and then the supernatant was gently aspirated after incubation for three hours at $37^{\circ} \mathrm{C}$. Eventually, $200 \mu \mathrm{L}$ of DMSO (dimethyl sulfoxide) was added to each well and oscillated for ten minutes to dissolve formazan crystals. Absorbance of OD from the plates was read at $550 \mathrm{~nm}$ through a UV spectrophotometer at 24, 48 and 72 hours after transfection. The assay was performed three times independently.

\section{Luciferase reporter gene assay}

For the reporter gene assay, cells seeded in 24well plates were transfected with the firefly luciferase reporter gene construct (TOP or FOP; 200ng), and 1ng of pRL-SV40 Renilla luciferase (as an internal control). Cell extracts were prepared 24 hours after transfection, and luciferase activity was measured using the DualLuciferase Reporter Assay System (Promega, USA).

\section{Coculture with Dkk1 and Wnt-5a.}

We cultured NCl-H23-CTHRC1 cells together with Dkk1 (R\&D, USA) at the concentration of $15 \mathrm{ng} / \mathrm{mL}$.
Wnt-5a-conditioned medium (Wnt-5a-CM) was produced from $\mathrm{L}$ cells transfected with pGKWnt-5a. The medium was centrifuged at $1,000 \mathrm{~g}$ for 15 minutes and filtered through a nitrocellulose membrane. Then, cells were treated with Wnt-5a CM for 24 hours and Wnt signaling was monitored by various assays, including Western blotting and luciferase reporter gene assays.

\section{Statistical analysis}

Statistical analysis was undertaken with SPSS 16.0 software. The Pearson $\chi^{2}$ test was used to assess the correlation between CTHRC1 expression and clinicopathological parameters. Unpaired two-tailed Student's t-test was used to determine the statistical relevance between groups. Survival curves were plotted using the Kaplan-Meier method and compared with the log-rank test. Univariate and multivariate analyses were carried out by the Cox proportional hazards regression model. P values of less than 0.05 were considered statistically significant.

\section{ACKNOWLEDGEMENTS}

This work was financially supported by the National Natural Science Foundation of China (No. 30900650/ H1615， 81372501/H1615， 81172232/H1615 and $81172564 / \mathrm{H} 1625)$ and the Guangdong Natural Science Foundation (No. S2012010008378, S2013010015327).

\section{AUTHOR CONTRIBUTIONS}

Conception and design: Zunfu Ke, Liantang Wang. Development of methodology: Weiling He, Yuefeng Wang and Xuefeng Guo. Acquisition of data: Zunfu Ke. Analysis and interpretation of data: Zunfu Ke. Writing, review and/ or revision of the manuscript: Zunfu Ke, Yuanhui Lai and Sharon Chen. Administrative, technical or material support: Shuhua Li. Study supervision: Zunfu Ke and Liantang Wang. All authors read and approved the final manuscript.

\section{REFERENCES}

1. Siegel R, Naishadham D, Jemal A. Cancer statistics, 2012. CA Cancer J Clin. 2012; 62:10-29.

2. She J, Yang P, Hong Q, Bai C. Lung cancer in China: challenges and interventions. Chest. 2013; 143:1117-1126.

3. Jemal A, Siegel R, Ward E, Hao Y, Xu J, Thun MJ. Cancer statistics, 2009. CA Cancer J Clin. 2009; 59: 225-249.

4. Reck M. What future opportunities may immuno-oncology provide for improving the treatment of patients with lung cancer? Ann Oncol. 2012; 23:viii28-34. 
5. Miller YE. Pathogenesis of lung cancer: 100 year report. Am J Respir Cell Mol Biol. 2005; 33:216-223.

6. Hood JD, Cheresh DA. Role of integrins in cell invasion and migration. Nat Rev Cancer. 2002; 2:91-100.

7. Nobes CD, Hall A. Rho, rac, and cdc42 GTPases regulate the assembly of multimolecular focal complexes associated with actin stress fibers, lamellipodia, and filopodia. Cell. 1995; 81:53-62.

8. Leber MF, Efferth T. Molecular principles of cancer invasion and metastasis (review). Int J Oncol. 2009; 34:881-895.

9. Gupta GP, Massagué J. Cancer metastasis: building a framework. Cell. 2006; 127:679-695.

10. Vogelstein B, Kinzler KW. Cancer genes and the pathways they control. Nat Med. 2004; 10:789-799.

11. Crawford HC, Fingleton BM, Rudolph-Owen LA, Goss KJ, Rubinfeld B, Polakis P, Matrisian LM. The metalloproteinase matrilysin is a target of beta-catenin transactivation in intestinal tumors. Oncogene. 1999; 18:2883-2891.

12. Marchenko ND, Marchenko GN, Weinreb RN, Lindsey JD, Kyshtoobayeva A, Crawford HC, Strongin AY. Beta-catenin regulates the gene of MMP-26, a novel metalloproteinase expressed both in carcinomas and normal epithelial cells. Int J Biochem Cell Biol. 2004; 36:942-956.

13. Pacheco-Pinedo EC, Durham AC, Stewart KM, Goss AM, Lu MM, Demayo FJ, Morrisey EE. Wnt/ $\beta$-catenin signaling accelerates mouse lung tumorigenesis by imposing an embryonic distal progenitor phenotype on lung epithelium. J Clin Invest. 2011; 121:1935-1945.

14. Diatchenko L, Lau YF, Campbell AP, Chenchik A, Moqadam F, Huang B, Lukyanov S, Lukyanov K, Gurskaya N, Sverdlov ED, Siebert PD. Suppression subtractive hybridization: a method for generating differentially regulated or tissue-specific cDNA probes and libraries. Proc Natl Acad Sci U S A. 1996; 93:6025-6030.

15. Durmus T, LeClair RJ, Park KS, Terzic A, Yoon JK, Lindner V. Expression analysis of the novel gene collagen triple helix repeat containing-1 (Cthrc1). Gene Expr Pattern. 2006; 6:935-940.

16. LeClair R, Lindner V. The role of collagen triple helix repeat containing 1 in injured arteries, collagen expression, and transforming growth factor beta signaling. Trends Cardiovasc Med. 2007; 17:202-205.

17. Tang L, Dai DL, Su M, Martinka M, Li G, Zhou Y. Aberrant expression of collagen triple helix repeat containing 1 in human solid cancers. Clin Cancer Res. 2006; 12:3716-3722.

18. Turashvili G, Bouchal J, Baumforth K, Wei W, Dziechciarkova M, Ehrmann J, Klein J, Fridman E, Skarda J, Srovnal J, Hajduch M, Murray P, Kolar Z. Novel markers for differentiation of lobular and ductal invasive breast carcinomas by laser microdissection and microarray analysis. BMC Cancer. 2007; 7:55.

19. Ip W, Wellman-Labadie O, Tang L, Su M, Yu R, Dutz J, Wang Y, Huang S, Zhang X, Huang C, Zhou Y. Collagen triple helix repeat containing 1 promotes melanoma cell adhesion and survival. J Cutan Med Surg. 2011; 15:103-110.

20. Yamamoto S, Nishimura O, Misaki K, Nishita M, Minami Y, Yonemura S, Tarui H, Sasaki H. Cthrc1 selectively activates the planar cell polarity pathway of Wnt signaling by stabilizing the Wnt-receptor complex. Dev Cell. 2008; 15:23-36.

21. Pyagay P, Heroult M, Wang Q, Lehnert W, Belden J, Liaw L, Friesel RE, Lindner V. Collagen triple helix repeat containing 1 , a novel secreted protein in injured and diseased arteries, inhibits collagen expression and promotes cell migration. Circ Res. 2005; 96:261-268.

22. Kharaishvili G, Cizkova M, Bouchalova K, Mgebrishvili G, Kolar Z, Bouchal J. Collagen triple helix repeat containing 1 protein, periostin and versican in primary and metastatic breast cancer: an immunohistochemical study. J Clin Pathol. 2011; 64:977-982.

23. Logan CY, Nusse R. The Wnt signaling pathway in development and disease. Annu Rev Cell Dev Biol. 2004; 20:781-810.

24. Govindan R, Ding L, Griffith M, Subramanian J, Dees ND, Kanchi KL, Maher CA, Fulton R, Fulton L, Wallis J, Chen K, Walker J, McDonald S, Bose R, Ornitz D, Xiong D, You M, Dooling DJ, Watson M, Mardis ER, Wilson RK. Genomic landscape of non-small cell lung cancer in smokers and never-smokers. Cell. 2012; 150:1121-1134.

25. Kim HC, Kim YS, Oh HW, Kim K, Oh SS, Kim JT, Kim BY, Lee SJ, Choe YK, Kim DH, Kim SH, Chae SW, Kim KD, Lee HG. Collagen triple helix repeat containing 1 (CTHRC1) acts via ERK-dependent induction of MMP9 to promote invasion of colorectal cancer cells. Oncotarget. 2014; 5:519-529.

26. Ma MZ, Zhuang C, Yang XM, Zhang ZZ, Ma H, Zhang WM, You H, Qin W, Gu J, Yang S, Cao H, Zhang ZG. CTHRC1 acts as a prognostic factor and promotes invasiveness of gastrointestinal stromal tumors by activating Wnt/PCP-Rho signaling. Neoplasia. 2014; 16:265-278.e1-13.

27. Chen YL, Wang TH, Hsu HC, Yuan RH, Jeng YM. Overexpression of CTHRC1 in hepatocellular carcinoma promotes tumor invasion and predicts poor prognosis. PLoS One. 2013; 8:e70324.

28. Park EH, Kim S, Jo JY, Kim SJ, Hwang Y, Kim JM, Song SY, Lee DK, Koh SS. Collagen triple helix repeat containing-1 promotes pancreatic cancer progression by regulating migration and adhesion of tumor cells. Carcinogenesis. 2013; 34:694-702. 
29. Karner C, Wharton KA Jr, Carroll TJ. Planar cell polarity and vertebrate organogenesis. Semin Cell Dev Biol. 2006; 17:194-203.

30. Moon RT, Bowerman B, Boutros M, Perrimon N. The promise and perils of Wnt signaling through beta-catenin. Science. 2002; 296:1644-1646.

31. Chien AJ, Conrad WH, Moon RT. A Wnt survival guide: from flies to human disease. J Invest Dermatol. 2009; 129:1614-1627.

32. Giles RH, van Es JH, Clevers H. Caught up in a Wnt storm: Wnt signaling in cancer. Biochim Biophys Acta. 2003; 1653:1-24.

33. Liu C, Li Y, Semenov M, Han C, Baeg GH, Tan Y, Zhang $\mathrm{Z}$, Lin $\mathrm{X}$, He $\mathrm{X}$. Control of beta-catenin phosphorylation/degradation by a dual-kinase mechanism. Cell. 2002; 108:837-847.
34. Embi N, Rylatt DB, Cohen P. Glycogen synthase kinase-3 from rabbit skeletal muscle. Separation from cyclic-AMPdependent protein kinase and phosphorylase kinase. Eur J Biochem. 1980; 107:519-527.

35. Jope RS, Johnson GV. The glamour and gloom of glycogen synthase kinase-3. Trends Biochem Sci. 2004; 29:95-102.

36. Doble BW, Woodgett JR. GSK-3: tricks of the trade for a multi-tasking kinase. J Cell Sci. 2003; 116: $1175-1186$.

37. Woodgett JR. Molecular cloning and expression of glycogen synthase kinase-3/factor A. EMBO J. 1990; 9:2431-2438.

38. Ke Z, Zhang X, Ma L, Wang L. Expression of DPC4/ Smad4 in non-small-cell lung carcinoma and its relationship with angiogenesis. Neoplasma. 2008; 55:323-329. 